\title{
Fatty corner lesions in T1-weighted magnetic resonance imaging as an alternative to sacroiliitis for diagnosis of axial spondyloarthritis
}

\author{
Ho Yin Chung ${ }^{1}$, Rachel Sze Wan Yiu', Shirley Chiu Wai Chan ${ }^{1}$, Kam Ho Lee ${ }^{2}$ and Chak Sing Lau ${ }^{1 *}$ (D)
}

\begin{abstract}
Background: A fatty corner lesion ( $F C L)$ is a well-demarcated fat infiltration in the corner of a vertebral body on T1 magnetic resonance imaging (MRI) sequence. It has been reported to be useful in the diagnosis of axial spondyloarthritis (axSpA). Our objective is to systematically evaluate the diagnostic accuracy of FCLs in tertiary centre patients with chronic back pain.

Method: Two hundred and thirty eight axSpA patients and 62 non-axSpA patients with back pain were recruited from five rheumatology centres. Clinical, biochemical, and radiological parameters were collected and all patients underwent a MRI of the spine and sacroiliac (SI) joints. FCLs in vertebral bodies from C4 to L5 were scored. The number and location of FCLs were clustered together to determine an optimal combination for diagnosis. Results were compared with expert diagnosis as the "gold standard".

Results: FCLs of the anterior whole spine (AUC 0.62; $p=0.003$ ) and anterior thoracic spine (AUC 0.64; $p=0.001$ ) had diagnostic significance. Incorporating at least 5 whole spine FCLs into the imaging criteria of the Assessment of SpondyloArthritis international Society (ASAS) criteria for axSpA yielded a sensitivity of 91.6\% and specificity of 91.9\%. Similarly, applying at least 3 anterior thoracic FCLs to the imaging criteria of the ASAS axial SpA criteria yielded a sensitivity of $92.0 \%$ and specificity of $93.5 \%$.
\end{abstract}

Conclusion: FCLs could be used to diagnose axial SpA. The presence of at least 3 anterior thoracic FCLs in T1-weighted MRI spine suggests a diagnosis of axial SpA without additional MRI of the SI joints.

Trial registration: The cohort has been registered in the clinical trial registry of the University of Hong Kong (HKUCTR2087).

Keywords: Spondyloarthropathies, Magnetic resonance imaging, Diagnosis, Back pain, Spine

\section{Background}

The Assessment of SpondyloArthritis international Society (ASAS) classification criteria for axial spondyloarthritis (axSpA) in $2009[1,2]$ was the first to incorporate sacroiliitis on magnetic resonance imaging (MRI) in its imaging criteria, which resulted in early diagnosis [3]. In addition to inflammation, MRI has been used to identify other lesions in axSpA. The "MR corner sign", which includes both

\footnotetext{
* Correspondence: cslau@hku.hk

'Division of Rheumatology and Clinical Immunology, Department of Medicine, the University of Hong Kong, Pokfulam, Hong Kong, China Full list of author information is available at the end of the article
}

inflammatory and non-inflammatory lesions of the spine, was found to be specific for ankylosing spondylitis [4] prior to the introduction of the ASAS criteria. Fatty corner lesions (FCLs) in the lumbar spine were initially suggested in diagnosis of axSpA, and Bennett et al. had proposed the use of whole spine FCLs [5].

FCLs have not been included in the ASAS classification criteria due inconclusive evidence of diagnostic utility. In 2015, Weber et al. found that when used alone, whole spine FCLs showed poor positive and negative likelihood ratios (LR) in 130 patients with axSpA (for $\geq 6$ FCLs, positive LR were 2.49-2.53; negative LR were 0.64-0.68) [6].

(c) The Author(s). 2019 Open Access This article is distributed under the terms of the Creative Commons Attribution 4.0 International License (http://creativecommons.org/licenses/by/4.0/), which permits unrestricted use, distribution, and reproduction in any medium, provided you give appropriate credit to the original author(s) and the source, provide a link to the Creative Commons license, and indicate if changes were made. The Creative Commons Public Domain Dedication waiver (http://creativecommons.org/publicdomain/zero/1.0/) applies to the data made available in this article, unless otherwise stated. 
However, the SpondyloArthritis Caught Early (SPACE) cohort of 287 patients with chronic back pain in Europe found promising data for the diagnostic utility of FCLs. The presence of at least 5 fatty lesions on MRI spine had the ability to identify axSpA with a specificity of $95 \%$. The proportion of patients with ASAS imaging arm criteria positive axSpA with at least 5 fatty lesions ranged from 18.2 to $21.6 \%$. [7]. In view of apparently conflicting findings, this study aims to systematically evaluate the diagnostic utility of FCLs at different vertebral levels in a large tertiary cohort of patients with chronic back pain.

\section{Methods}

This is a multicentre retrospective study of prospectively acquired data. The acquired data was from a cohort originally used to evaluate the utility of diffusion weighted imaging (DWI) in the diagnosis and clinical monitoring of axSpA. The cohort has been registered in the clinical trial registry of the University of Hong Kong (HKUCTR-2087). Detailed methods have been described in our previous publication [8]. Recruitment started in May 2016 and is on-going. Data analysis was performed on results up to Feb 2018.

\section{Patient recruitment}

Two groups of patients were recruited consecutively from five different rheumatology centres (Queen Mary Hospital, Tung Wah Hospital, Grantham Hospital, Pamela Youde Nethersole Eastern Hospital, and Tseung Kwan O Hospital) in Hong Kong. The first group consisted of 238 patients with a known diagnosis of axSpA and chronic back pain. This group was termed the "axSpA group". The second group was the control group. It consisted of 62 patients with a known diagnosis of diseases other than SpA. The group included 43 patients with known spinal degeneration, 1 patient with fibromyalgia, 1 patient with tuberculosis of spine and 17 patients with non-specific back pain and was termed the "non-axSpA group". Written informed consent was obtained from all subjects. Exclusion criteria included: i) pregnancy, ii) inability or refusal to undergo MRI examination, iii) inability to give written consent.

\section{Clinical and demographic data}

Clinical and demographic data were collected from recruited patients. These included: age, sex, history of smoking and regular use of alcohol, duration and severity of back pain (scored on a 1-to-10 numeric rating scale), and family history of SpA. Physical examination was performed for tender/ swollen joint counts, Maastrich Ankylosing Spondylitis Enthesitis Score (MASES) [9], Bath Ankylosing Spondylitis Metrology Index (BASMI) [10], and number of dactylitis sites. All patients completed three questionnaires: Bath Ankylosing Spondylitis Disease Activity Index (BASDAI) [11], Bath Ankylosing Spondylitis Functional Index
(BASFI) [12], and Bath Ankylosing Spondylitis Global Index (BASGI) [13]. Blood parameters including human leucocyte antigen (HLA) B27, C-reactive protein (CRP) and erythrocyte sedimentation rate (ESR) were recorded. Ankylosing Spondylitis Disease Activity Index (ASDAS) were calculated based on both ESR (ASDAS-ESR) and CRP (ASDAS-CRP) [14, 15].

\section{Radiographic grading of lumbosacral (LS) spine and sacroiliac (SI) joints}

Anteroposterior (AP) views of LS spine radiographs were done in all patients. SI joint radiographs were graded according to the Modified New York (MNY) criteria [16]: 0, normal; 1 suspicious; 2, sclerosis/ erosion with normal joint space; 3 , sclerosis/ erosion with change in joint space or partial ankylosis; 4, complete fusion. Bilateral sacroiliitis grade 2 or above, or unilateral sacroiliitis grade 3 or above was defined as radiological AS. The gradings were only used for describing the percentage of radiological AS and not involved in the analyses.

\section{MRI scoring of the spine and SI joints}

All recruited patients underwent whole spine and bilateral SI joint MRI examinations using a $3 \mathrm{~T}$ Achieva scanner (Philips Healthcare, Best, the Netherlands). A torso coil was used to image both the spine and sacroiliac joints. Short tau inversion recovery (STIR) sequence, T1 weighted, and DWI were obtained consecutively in the same MRI examination. Technical parameters for STIR images are summarized in Table 1 . The imaging parameters and others (including DWI) have been reported in our previous publication [8].

MRI of SI joints were scored according to the Spondyloarthritis Research Consortium of Canada (SPARCC) scoring system [17] by two independent readers (HYC, SCWC) blinded to clinical, radiological parameters and T1-weighted MRI spine. Positive sacroiliitis in STIR images was defined as: one signal of subchondral bone marrow edema on at least 2 slides, or more than one signal on a single slice, according to the ASAS handbook [18]. True sacroiliitis required identification by both readers. Similarly, FCLs in STIR and T1-weighted MRI spine were read by two independent readers (HYC, RSWY), blinded to

Table 1 Imaging parameters for STIR, T1, and DWI sequences

\begin{tabular}{llll}
\hline & STIR & T1 & DWI \\
\hline TR/TE $(\mathrm{ms})$ & $5000 / 80$ & $800 / 8$ & $4000 / 90$ \\
Field-of-view $\left(\mathrm{mm}^{2}\right)$ & $150 / 240$ & $150 \times 240$ & $300 / 241$ \\
Matrix size & $152 \times 157$ & $168 \times 217$ & $124 \times 100$ \\
Slice thickness $(\mathrm{mm})$ & 3.5 & 3.5 & 4 \\
SENSE factor & N/A & N/A & 2 \\
\hline
\end{tabular}

$T R$ repetition time, TE echo time, SENSE sensitivity encoding, STIR short tau inversion recovery, DWI diffusion weighted imaging, N/A not applicable 
clinical, radiological parameters and STIR images of SI joints. An FCL was defined as a well-demarcated triangular lesion, hyper-intense on T1-weighted images and suppressed on STIR sequences, present on at least one sagittal slice in the corner of any vertebral body as previously described by Bennett et al. (Fig. 1) [5]. As the upper vertebrae have different anatomical shapes and could be difficult to score, our scorings involved only C4 to L5 vertebral bodies. Both anterior and posterior vertebral corners were scored.

\section{Statistical analyses}

Student's t-tests and chi square tests were used to compare baseline demographic and clinical characteristics in the axSpA and non-axSpA groups. The Student's t-test was also used to compare the number of FCLs in the two groups. At the vertebral levels in which significant differences were found, receiver operating characteristic (ROC) curves were constructed. The area under the curve (AUC) was used to determine the optimal cut off number of FCLs for diagnostic utility. This was done by selecting the number with the highest sensitivity corresponding to a specificity $(95.2 \%$ as stated in the results section) greater than that of the imaging arm of the ASAS axSpA criteria in order not to jeopardize the specificity of the new criteria.

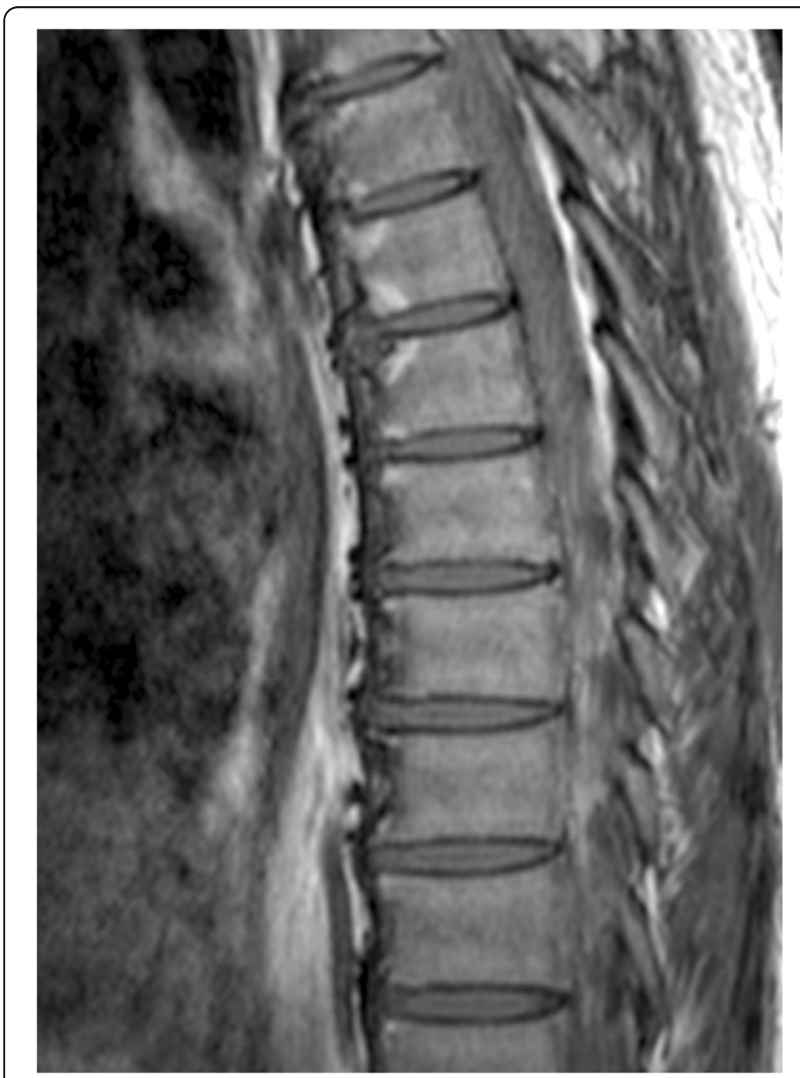

Fig. 1 Fatty corner lesions
Upon 1) replacing the sacroiliitis on imaging criteria in ASAS criteria with the optimal cut off number of FCLs and 2) including the optimal cut off number of FCLs into the ASAS criteria. We determined their sensitivity, specificity, positive predictive value (PPV), negative predictive value (NPV), positive likelihood ratio $(\mathrm{LR}+)$ and negative likelihood ratio (LR-). Effect of LR+ was defined as none, slight increase, moderate increase, large increase for the groups with values $1-2,2-5,5-10$, and $>10$ respectively. Similarly, effect of LR- was defined as none, slight decrease, moderate decrease, large decrease for the groups with values $1-0.5,0.5-0.2,0.2-0.1$, and $<0.1$ respectively.

Cohen's kappa was used to measure agreement in MRI scoring (FCLs and sacroiliitis) by the two readers. Value ranges of $0.00-0.20,0.21-0.40,0.41-0.60,0.61-0.80$, 0.81-1.00 represented slight, fair, moderate, substantial, and near perfect agreement respectively [19].

\section{Results}

Clinical history, physical examination and laboratory findings of the axSpA group and non-axSpA group are described in Table 2. When compared to the non-axSpA group, axSpA patients had longer duration of back pain $(12.0 \pm 11.4$ vs $7.1 \pm 8.4 ; p=0.002)$, higher levels of CRP $(1.07 \pm 1.94$ vs $0.37 \pm 1.27 ; p=0.001)$, male predominance $(55.0 \%$ vs $26.2 \% ; p<0.001)$, and greater proportion with HLA-B27 positivity ( $76.8 \%$ vs $16.0 \%$; $p<0.001)$.

The agreement in identifying FCLs between the two readers (HYC, RSWY) was substantial (Cohen's kappa $0.65 \pm 0.03$ ). In the axSpA group, FCLs were preferentially distributed at the thoracic level (585/913 or $64.1 \%)$, in contrast to distribution at the lumbar level $(31 / 54$ or $57.4 \%$ ) in the non-axSpA group (Fig. 2). Overall, more FCLs were found in the axSpA group than the non-axSpA group ( $3.8 \pm 6.8$ vs $0.9 \pm 2.2 ; p<0.001)$ (Table 3 ).

ROC curves were used to determine the diagnostic utility of FCLs at different vertebral levels (Table 4). Whole spine FCLs (AUC 0.615, 95\% CI 0.545; 0.685, $p$-value 0.01), thoracic spine FCLs (AUC 0.638, 95\% CI 0.570; $0.707, p$-value 0.001), anterior whole spine FCLs (AUC 0.622 , 95\% CI 0.551; 0.692, $p$-value 0.003), and anterior thoracic FCLs (AUC 0.640, 95\% CI 0.572; 0.708, $p$-value 0.001 ) all had the ability to differentiate between patients with and without axSpA. At the lumbar spinal level, anterior FCLs showed only a tendency to be able to differentiate between patients with and without axSpA (AUC 0.576, 95\% CI 0.500; 0.652, $p$-value 0.07).

Agreement between the two readers in reading sacroiliitis on MRI according to the ASAS criteria was substantial (Cohen's kappa $0.79 \pm 0.04$ ). From our analyses, posterior FCLs had no diagnostic utility. The diagnostic value of whole spine FCLs was predominantly contributed by that from anterior FCLs (Table 3), therefore only anterior FCLs were used to determine optimal cut-off values. The 
Table 2 Clinical history, physical examination and laboratory findings of the studied patients

\begin{tabular}{|c|c|c|c|}
\hline & $\begin{array}{l}\text { axSpA }(n=238) \\
\text { Mean } \pm \text { SD/ (percentage) }\end{array}$ & $\begin{array}{l}\text { Non-axSpA }(n=62) \\
\text { Mean } \pm \text { SD/ (percentage) }\end{array}$ & $p$-value \\
\hline Age (years) & $43.5 \pm 13.1$ & $47.1 \pm 17.1$ & 0.13 \\
\hline Duration of back pain (years) & $12.0 \pm 11.4$ & $7.1 \pm 8.4$ & 0.002 \\
\hline Male sex & $131(55.0 \%)$ & $16(26.2 \%)$ & $<0.001$ \\
\hline HLA-B27 positivity & $169(76.8 \%)$ & $8(16.0 \%)$ & $<0.001$ \\
\hline Smoker & $66(27.8 \%)$ & $11(19.0 \%)$ & 0.17 \\
\hline Regular alcohol use & $27(11.6 \%)$ & $5(5.3 \%)$ & 0.16 \\
\hline Radiologic AS & $149(62.9 \%)$ & $0(0.0 \%)$ & $<0.001$ \\
\hline Back pain NRS & $5.74 \pm 2.35$ & $6.10 \pm 2.27$ & 0.32 \\
\hline BASDAI & $4.82 \pm 2.00$ & NA & - \\
\hline BASFI & $3.12 \pm 2.44$ & NA & - \\
\hline Tender joint count & $1.57 \pm 3.02$ & $2.74 \pm 4.66$ & 0.07 \\
\hline Swollen joint count & $0.60 \pm 1.57$ & $0.97 \pm 2.58$ & 0.31 \\
\hline Enthesitis score & $0.43 \pm 0.90$ & $0.58 \pm 1.80$ & 0.53 \\
\hline Number of dactylitis & $0.19 \pm 1.02$ & $0.26 \pm 1.47$ & 0.66 \\
\hline BASMI & $3.44 \pm 1.65$ & NA & - \\
\hline ESR (mm/hr) & $32.9 \pm 25.6$ & $34.5 \pm 26.2$ & 0.68 \\
\hline CRP (mg/L) & $1.07 \pm 1.94$ & $0.37 \pm 1.27$ & 0.001 \\
\hline Presence of FCL at C-spine & $28(11.8 \%)$ & $2(3.2 \%)$ & 0.05 \\
\hline Presence of FCL at T-spine & 91 (38.2\%) & $8(12.9 \%)$ & $<0.001$ \\
\hline Presence of FCL at L-spine & 85 (35.7\%) & $16(25.8 \%)$ & 0.14 \\
\hline BASGI & $5.38 \pm 2.49$ & NA & - \\
\hline ASDAS ESR & $3.03 \pm 1.02$ & NA & - \\
\hline ASDAS CRP & $1.91 \pm 0.83$ & NA & - \\
\hline
\end{tabular}

HLA Human Leucocyte Antigen, ASAS Assessment of SpondyloArthritis international Society, IBP inflammatory back pain, axSpA axial spondyloarthritis, AS ankylosing spondylitis, NRS numerical rating scale, BASDAl Bath Ankylosing Spondylitis Disease Activity Index, BASFI Bath Ankylosing Spondylitis Functional Index, $B A S M I$ Bath Ankylosing Spondylitis Metrology Index, ESR erythrocyte sedimentation rate, CRP C-reactive protein, BASGI Bath Ankylosing Spondylitis Global Index, ASDAS Ankylosing Spondylitis Disease Activity Index, FCL fatty corner lesion, $C$-spine cervical spine, $T$-spine thoracic spine, $L$-spine lumbar spine, NA not applicable

optimal number of FCLs corresponded with a specificity greater than that of the ASAS criteria. The ASAS criteria had a sensitivity of $90.3 \%$ and specificity of $93.5 \%$ while its imaging arm had a sensitivity of $84.5 \%$ and specificity of 95.2\%. The different cut-off thresholds of FCLs are presented in the lower part of Table 4. With a specificity greater than $95.2 \%$, the optimal cut-off values for anterior whole spine FCLs was $\geq 5$, and anterior thoracic FCLs was $\geq 3$. Different scenarios of the ASAS criteria in diagnosing axSpA are presented in Table 5 . The greatest sensitivity was obtained by including $\geq 3$ anterior thoracic FCLs to the imaging arm of the ASAS axSpA criteria.

\section{Presence of FCLs without sacroiliitis}

Thirteen patients (out of 235 patients or 5.5\%) with expert diagnosis of $\mathrm{SpA}$, had $\geq 3$ anterior thoracic FCLs but without sacroiliitis on both x-ray and MRI. Similarly, 12 patients (out of 235 patients or 5.1\%) with expert diagnosis of SpA, had $\geq 5$ whole spine FCLs but without sacroiliitis on both $\mathrm{x}$-ray and MRI.

\section{Discussion}

We evaluated and reported the diagnostic utility of anterior FCLs on T1 MRI in axSpA. In patients with features of SpA, replacing sacroiliitis on imaging with FCLs had only fair sensitivity but good specificity. Aadding FCLs into the imaging entry criteria only slightly improved the sensitivity.

Acute inflammatory lesions in the vertebrae affects the thoracic spine preferentially over the cervical or lumbar spine [20, 21]. Baraliakos et al. [21] found definite thoracic spinal inflammation in $74 \%$ of AS patients, predominantly at the T7-T8 vertebral unit. As fatty changes are thought to be the result of inflammation [22], it may be deduced that FCLs would also occur predominantly in the thoracic spine. In fact, Kim et al. had reported FCLs to be more common in the anterior part of the lower thoracolumbar spine [4]. Bennett et al. also reported FCLs to be more common in the thoracic spine [5]. Our results are consistent with their reports.

FCLs at different vertebral levels have variable diagnostic utility. Kim et al. proposed using lumbar FCLs for 


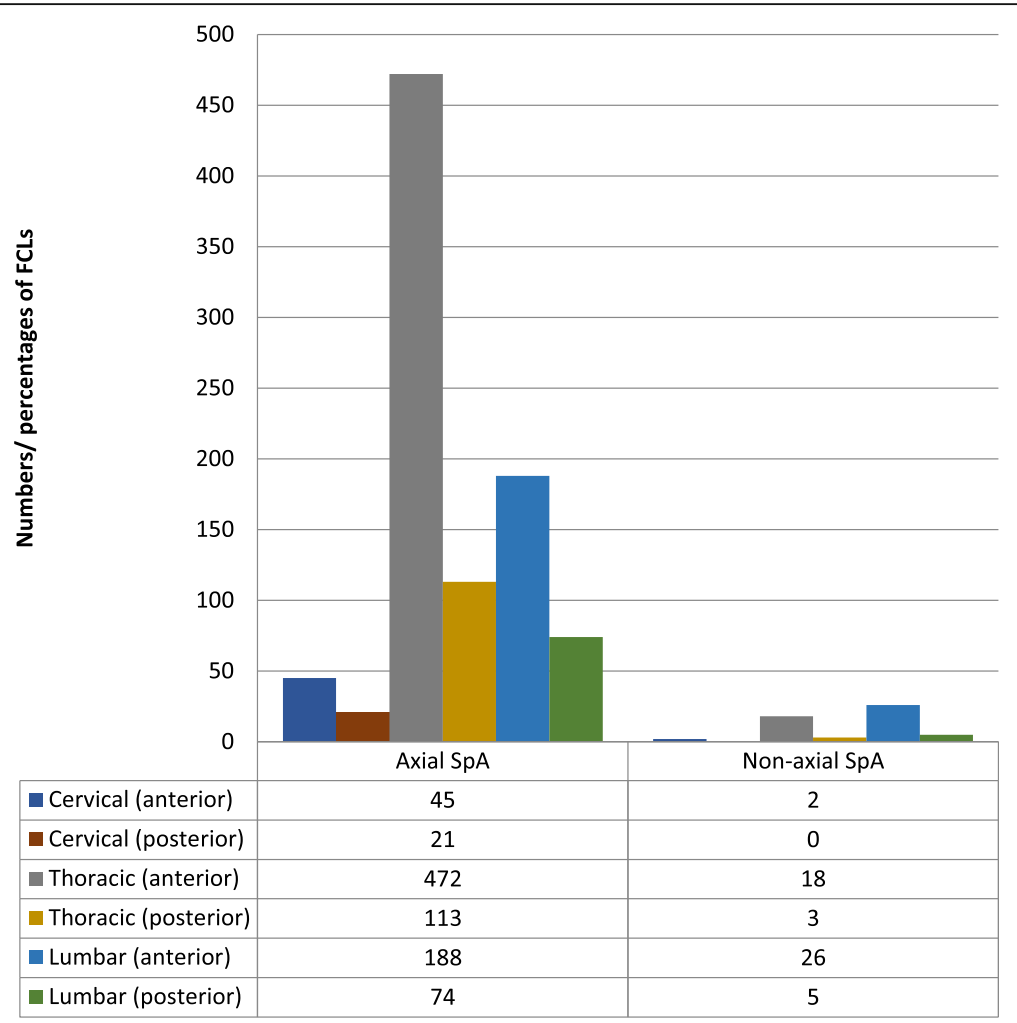

Fig. 2 Distribution of FCLs in axial SpA and non-axial SpA groups

diagnosis of AS [4]. However, our data showed only a tendency for lumbar FCLs to aid diagnosis. Weber et al. showed that whole spine FCLs $\geq 6$ has poor likelihood ratios [6] as a diagnostic criteria. Its specificity of 81$82 \%$ was significantly less than that found in our study. In contrast, our data was more compatible with Kim et al. [4], and subsequently the SPACE cohort [7], in which whole spine FCLs $\geq 5$ had a specificity of $\geq 95 \%$ in discriminating between axSpA and non-axSpA. Overall, lumbar and whole spine FCLs show variable diagnostic utility. Although FCLs are observed in axSpA, they are also present in degenerative and other spinal disorders [23] which could contribute to the differences in specificity. Among all vertebral levels, the thoracic spine is the least affected by degeneration [24, 25], rendering a more accurate diagnostic tool for axSpA.

The differential utility between anterior and posterior FCLs in diagnosis of axSpA is a new finding in our study. Anterior FCLs contributed predominantly to the overall diagnostic utility in whole spine FCLs because they were present much more frequently than posterior FCLs. Although both whole spine FCLs and anterior spine FCLs were useful in axSpA diagnosis, the former group was not included in analyses because of its lower AUC. Posterior FCLs were not useful owing to its low frequency of occurrence.

Unlike Weber et al. and the SPACE cohort, we did not use the Canada-Denmark scoring system [26, 27] because we wanted to differentiate the usefulness of FCLs at individual vertebral levels and bisected into anterior and posterior spine. In contrast, the Canada-Denmark scoring system gives a summative score of the whole spine. C2, C3 and S1 vertebral bodies were not evaluated in this study. Using our individual scoring, we also reported an optimum cut-off of $\geq 5$ anterior whole spine FCLs, which is similar to previous studies [7].

Table 3 Number of FCLs in axial SpA and non-axial SpA groups

\begin{tabular}{llll}
\hline & Mean FCLs in axSpA group \pm SD & Mean FCLs in non-axSpA group $\pm S D$ & $p$-value \\
\hline All spinal lesions & $3.8 \pm 6.8$ & $0.9 \pm 2.2$ & $<0.001$ \\
Anterior lesions & $3.0 \pm 5.1$ & $0.8 \pm 1.9$ & $<0.001$ \\
Posterior lesions & $0.9 \pm 2.4$ & $0.1 \pm 0.5$ & $<0.001$ \\
\hline
\end{tabular}

FCL fatty corner lesion, axSpA axial spondyloarthritis, $S D$ standard deviation 
Table 4 Diagnostic utility and cut-off values of FCLs at different spinal levels in diagnosing axSpA

\begin{tabular}{|c|c|c|c|c|}
\hline & AUC & Stand Error & $p$-value & $95 \% \mathrm{Cl}$ \\
\hline \multicolumn{5}{|l|}{ All spinal lesions } \\
\hline Whole spine & 0.615 & 0.036 & 0.01 & $0.545 ; 0.685$ \\
\hline Cervical & 0.544 & 0.039 & 0.29 & $0.467 ; 0.620$ \\
\hline Thoracic & 0.638 & 0.035 & 0.001 & $0.570 ; 0.707$ \\
\hline Lumbar & 0.561 & 0.039 & 0.14 & $0.486 ; 0.637$ \\
\hline \multicolumn{5}{|l|}{ Anterior lesions } \\
\hline Whole spine & 0.622 & 0.036 & 0.003 & $0.551 ; 0.692$ \\
\hline Cervical & 0.535 & 0.040 & 0.40 & $0.457 ; 0.612$ \\
\hline Thoracic & 0.640 & 0.035 & 0.001 & $0.572 ; 0.708$ \\
\hline Lumbar & 0.576 & 0.039 & 0.07 & $0.500 ; 0.652$ \\
\hline \multicolumn{5}{|l|}{ Posterior lesions } \\
\hline Whole spine & 0.567 & 0.038 & 0.11 & $0.492 ; 0.641$ \\
\hline Cervical & 0.521 & 0.040 & 0.61 & $0.442 ; 0.600$ \\
\hline Thoracic & 0.560 & 0.038 & 0.15 & $0.485 ; 0.635$ \\
\hline \multirow[t]{2}{*}{ Lumbar } & 0.527 & 0.040 & 0.52 & $0.449 ; 0.605$ \\
\hline & & $\begin{array}{l}\text { Cut-off threshold } \\
\text { (no of FCLs) }\end{array}$ & Sensitivity (\%) & Specificity (\%) \\
\hline \multirow{3}{*}{$\begin{array}{l}\text { Anterior whole } \\
\text { spine FCLs }\end{array}$} & & $\geq 3$ & 26.9 & 93.5 \\
\hline & & $\geq 4$ & 22.7 & 95.2 \\
\hline & & $\geq 5$ & 20.6 & 96.8 \\
\hline \multirow{3}{*}{$\begin{array}{l}\text { Anterior thoracic } \\
\text { FCLs }\end{array}$} & & $\geq 1$ & 31.5 & 90.3 \\
\hline & & $\geq 2$ & 26.5 & 95.2 \\
\hline & & $\geq 3$ & 18.5 & 98.4 \\
\hline
\end{tabular}

$F C L$ fatty corner lesion, axSpA axial spondyloarthritis, $A U C$ area under curve, $C l$ confidence interval

Of all the combinations of FCLs evaluated, we found that at least 3 anterior FCLs at the thoracic level had the greatest diagnostic utility in axSpA. However, routine use of T1 MRI for axSpA diagnosis is not recommended because replacing the sacroiliitis criteria with FCLs or including them into the ASAS axSpA criteria have not shown to improve diagnostic sensitivity. There were only a few patients with significant number of FCLs but no sacroiliitis on $\mathrm{x}$-ray or MRI. The high false positive values limit the sole use of FCLs in diagnosis of axSpA. However, in patients with clinical features of axSpA and incidental findings of at least 3 anterior thoracic FCLs or 5 whole spine FCLs in T1-weighted MRI would suggest a diagnosis of axSpA with specificity comparable to that of the ASAS criteria. This could assist diagnosis while avoiding the costs of additional MRI of the SI joints.

Table 5 Sensitivity, specificity, positive predictive value, negative predictive value, positive and negative likelihood ratio in different scenarios of the ASAS axSpA criteria in the diagnosis of axSpA

\begin{tabular}{|c|c|c|c|c|c|c|}
\hline & Sensitivity (\%) & Specificity (\%) & PPV (\%) & NPV (\%) & LR+ & LR- \\
\hline ASAS axSpA criteria (unaltered) & 90.3 & 93.5 & 90.3 & 93.5 & 13.89 & 0.10 \\
\hline Imaging arm only & 84.5 & 95.2 & 89.5 & 95.2 & 17.60 & 0.16 \\
\hline Sacroiliitis replaced by $\geq 3$ anterior thoracic FCLs & 80.6 & 93.4 & 98.0 & 55.3 & 12.2 & 0.21 \\
\hline Sacroiliitis replaced by $\geq 5$ anterior whole spine FCLs & 79.4 & 93.4 & 97.9 & 53.8 & 12.0 & 0.22 \\
\hline Sacroiliitis or $\geq 3$ anterior thoracic FCLs & 92.0 & 93.5 & 92.0 & 93.5 & 14.15 & 0.09 \\
\hline Sacroiliitis or $\geq 5$ anterior whole spine FCLs & 91.6 & 91.9 & 91.6 & 91.9 & 11.31 & 0.09 \\
\hline
\end{tabular}

PPV positive predictive value, NPV negative predictive value, $L R+$ positive likelihood ratio, $L R$ - negative likelihood ratio, $A S A S$ Assessment of SpondyloArthritis international Society, axSpA axial spondyloarthritis, $F C L$ fatty corner lesion 
A main problem with validation studies in axSpA is a lack of "gold standard" as there is no single investigation to define the disease. Similar to other international cohorts, we used diagnoses made by clinic rheumatologists as a gold standard. All studied patients had a clinical diagnosis before recruitment to minimise classification bias.

One of the limitations in our study was the small sample size in the control group. Another limitation was that the effect of age and disease duration were not taken into account during the evaluation of FCLs. According to Weber et al. and the SPACE cohort [7], aging may increase the number of FCLs [6]. However, patients in our study cohort were relatively young, and FCLs were uncommonly found in the non-axSpA group. Therefore, the effect of aging had minimal contributions to the prevalence of FCLs in our study. Since patients in tertiary care settings inherently have increased pre-test probability, the use of FCLs in patients with chronic back pain in primary care or in the general population might have different implications.

\section{Conclusion}

FCLs could be used to diagnose axSpA but routine use is not recommended. Notwithstanding this, in patients with clinical features of axSpA and the presence of at least 3 anterior thoracic FCLs or 5 whole spine FCLs in T1weighted MRI spine suggests a diagnosis of axSpA without additional MRI of the SI joints.

\section{Additional file}

Additional file 1: Using fatty corner lesions for diagnosis of axial spondyloarthritis data file. (SAV $55 \mathrm{~kb}$ )

\section{Acknowledgements \\ The authors would like to thank Ms. Wai Sum Anna Lee, Ms. Suet Kei Gladys Kwok, Ms. Lai Man Tang, Ms. Lui Mei Shan, and Ms. Wong Sai Ha of the Rheumatology Division, Queen Mary Hospital, for their assistance with patient recruitment. We would also like to thank the rheumatology teams of Pamela Youde Nethersole Eastern Hospital and Tseung Kwan O Hospital for their assistance in patient recruitment.}

\section{Funding}

This work is supported by Novartis research grant and the Hong Kong Society of Rheumatology Project Fund.

\section{Availability of data and materials}

All data generated or analysed during this study are included in this published article (Additional file 1).

\section{Authors' contributions \\ HYC is responsible for study design, patients recruitment, MRI scorings, data analyses and manuscript preparation. RSWY is responsible for MRI scorings, data analyses and manuscript preparation. SCWC is responsible for patients recruitment, MRI scorings and data analyses. $\mathrm{KHL}$ is responsible for $\mathrm{X}$-ray scorings, data analyses and manuscript preparation. CSL is responsible for study design, patents recruitment, data analyses and manuscript preparation. All authors read and approved the final manuscript.}

\section{Ethics approval and consent to participate}

The study was approved by the Institutional Review Boards of The University of Hong Kong, Pamela Youde Nethersole Eastern Hospital and Tseung Kwan O
Hospital (institutional review board reference no. UW 14-085). It was conducted in accordance with the Declaration of Helsinki and the guidance for good clinical practice, 30 November 2006. Written informed consent was obtained from all subjects.

\section{Consent for publication}

Not applicable.

\section{Competing interests}

The authors declare that they have no competing interests.

\section{Publisher's Note}

Springer Nature remains neutral with regard to jurisdictional claims in published maps and institutional affiliations.

\section{Author details}

${ }^{1}$ Division of Rheumatology and Clinical Immunology, Department of Medicine, the University of Hong Kong, Pokfulam, Hong Kong, China. ${ }^{2}$ Department of Radiology, Queen Mary Hospital, Hong Kong, China.

Received: 20 November 2018 Accepted: 26 April 2019

Published online: 30 May 2019

\section{References}

1. Rudwaleit M, Landewe R, van der Heijde D, et al. The development of assessment of SpondyloArthritis international society classification criteria for axial spondyloarthritis (part I): classification of paper patients by expert opinion including uncertainly appraisal. Ann Rheum Dis. 2009;68(6):770-6.

2. Rudwaleit M, van der Heijde $D$, Landewe R, et al. The development of assessment of SpondyloArthritis international society classification criteria for axial spondyloarthritis (part II): validation and final selection. Ann Rheum Dis. 2009;68(6):777-83.

3. Chung HY, Lau CS, Wu KP, Wong WS, Mok MY. Comparison of performance of the assessment of SpondyloArthritis international society, the European Spondyloarthropathy study group and the modified New York criteria in a cohort of Chinese patients with spondyloarthritis. Clin Rheumatol. 2011; 30(7):947-53.

4. Kim NR, Choi JY, Hong SH, et al. "MR corner sign": value for predicting presence of ankylosing spondylitis. AJR Am J Roentgenol. 2008;191(1):124-8.

5. Bennett AN, Rehman A, Hensor EM, et al. The fatty Romanus lesion: a noninflammatory spinal MRI lesion specific for axial spondyloarthropathy. Ann Rheum Dis. 2010;69(5):891-4.

6. Weber U, Zhao Z, Rufibach K, et al. Diagnostic utility of candidate definitions for demonstrating axial spondyloarthritis on magnetic resonance imaging of the spine. Arthritis Rheumatol. 2015;67(4):924-33.

7. de Hooge M, van den Berg R, Navarro-Compan V, et al. Patients with chronic back pain of short duration from the SPACE cohort: which MRI structural lesions in the sacroiliac joints and inflammatory and structural lesions in the spine are most specific for axial spondyloarthritis? Ann Rheum Dis. 2016;75(7):1308-14.

8. Chung HY, Xu X, Lau WW, et al. Comparing diffusion weighted imaging with clinical and blood parameters, and with short tau inversion recovery sequence in detecting spinal and sacroiliac joint inflammation in axial spondyloarthritis. Clin Exp Rheumatol. 2017;35(2):262-9.

9. Heuft-Dorenbosch L, Spoorenberg A, van Tubergen A, et al. Assessment of enthesitis in ankylosing spondylitis. Ann Rheum Dis. 2003;62(2):127-32.

10. Jones SD, Porter J, Garrett S, et al. A new scoring system for the Bath ankylosing spondylitis metrology index (BASMI). J Rheumatol. 1995;22:1609.

11. Garrett S, Jenkinson T, Kennedy LG, et al. A new approach to defining disease status in ankylosing spondylitis: the Bath ankylosing spondylitis disease activity index. J Rheumatol. 1994;21:2286-91.

12. Calin A, Garrett S, Whitelock H, et al. A new approach to defining functional ability in ankylosing spondylitis: the development of the Bath ankylosing spondylitis functional index. J Rheumatol. 1994;21:2281-5.

13. Jones SD, Steiner A, Garrett S, et al. The Bath ankylosing spondylitis patient global score (BAS-G). Br J Rheumatol. 1996;35:66-71.

14. Lukas C, Landewe R, Sieper J, et al. Development of an ASAS-endorsed disease activity score (ASDAS) in patients with ankylosing spondylitis. Ann Rheum Dis. 2009;68:18-24. 
15. Au YL, Wong WS, Mok MY, Chung HY, Chan E, Lau CS. Disease activity assessment in ankylosing spondylitis in a Chinese cohort: BASDAl or ASDAS? Clin Rheumatol. 2014;33(8):1127-34.

16. Van der Linden S, Valkenburg HA, Cats A. Evaluation of diagnostic criteria for ankylosing spondylitis. A proposal for modification of the New York criteria. Arthritis Rheum. 1984;27(4):361-8.

17. Maksymowych WP, Inman RD, Salonen D, et al. Spondyloarthritis research consortium of Canada magnetic resonance imaging index for assessment of sacroiliac joint inflammation in ankylosing spondylitis. Arthritis Rheum. 2005; 53:703-9.

18. Sieper J, Rudwaleit M, Baraliakos X, et al. The Assessment of SpondyloArthritis International Society (ASAS) handbook: a guide to assess spondyloarthritis. Ann Rheum Dis. 2009;68(Suppl 2):ii 1-44.

19. Landis JR, Koch GG. The measurement of observer agreement for categorical data. Biometrics. 1997;33(1):159-74

20. Bennett AN, Rehman A, Hensor EM, et al. Evaluation of the diagnostic utility of spinal magnetic resonance imaging in axial spondyloarthritis. Arthritis Rheum. 2009;60:1331-41.

21. Baraliakos $X$, Landewe $R$, Hermann $\mathrm{KG}$, et al. Inflammation in ankylosing spondylitis: a systematic description of the extent and frequency of acute spinal changes using magnetic resonance imaging. Ann Rheum Dis. 2005;64:730-4.

22. Song $\mathrm{IH}$, Hermann $\mathrm{KG}$, Haibel $\mathrm{H}$, et al. Inflammatory and fatty lesions in the spine and sacroiliac joints on whole body MRI in early axial spondyloarthritis - 3-year data of the ESTHER trial. Semin Arthritis Rheum. 2016;45(4):404-10.

23. Hermann KG, Althoff CE, Schneider U, Zuhlsdorf S, Lembcke A, Hamm B, et al. Spinal changes in patients with spondyloarthritis: comparison of MR imaging and radiographic appearances. Radiographics. 2005;25(3):559-69.

24. Wasserman MS, Guermazi A, Jarraya M, Engbretsen L, AbdelKader M, Roemer FW, et al. Evaluation of spine MRIs in athletes participating in the Rio de Janeiro 2016 summer Olympic games. BMJ Open Sport Exerc Med. 2018;4(1):e000335.

25. Xia W, Liu C, Duan S, Xu S, Wang K, Zhu Z, et al. The influence of spinalpelvic parameters on the prevalence of endplate Modic changes in degenerative thoracolumbar/ lumbar kyphosis patients. PLoS One. 2018; 13(5):e0197470.

26. Lambert RGW, Pedersen SJ, Maksymowych WP, et al. Active inflammatory lesions detected by magnetic resonance imaging in the spine of patients with spondyloarthritis --- definitions, assessment system, and reference image set. J Rheumatol Suppl. 2009;36:3-17.

27. Ostergaard M, Maksymowych WP, Pedersen SJ, et al. Structural lesions detected by magnetic resonance imaging in the spine of patients with spondyloarthritis --- definitions, assessment system and reference image set. J Rheumatol Suppl. 2009;36:18-34.

Ready to submit your research? Choose BMC and benefit from:

- fast, convenient online submission

- thorough peer review by experienced researchers in your field

- rapid publication on acceptance

- support for research data, including large and complex data types

- gold Open Access which fosters wider collaboration and increased citations

- maximum visibility for your research: over $100 \mathrm{M}$ website views per year

At $\mathrm{BMC}$, research is always in progress.

Learn more biomedcentral.com/submissions 